\title{
Anterior and inferior myocardial infarction Comparison with regard to some diseases and background factors
}

\author{
Victor Lindén \\ From the Institute for Community Medicine, University of Tromse, Norway
}

A pilot study has shown a significant positive correlation between anterior myocardial infarction and arterial hypertension, serum cholesterol values above $300 \mathrm{mg} / 100 \mathrm{ml}$, chronic lung diseases, diabetes mellitus, and the number of sibs who had suffered from myocardial infarction. The tendency for infarction to recur in the same site was significant at a 5 per cent level.

This work has its origin in the idea that patients suffering from anterior and inferior myocardial infarction may differ in certain respects. In arterial hypertension greater demands are made upon the left ventricle: patients with anterior infarction may, therefore, as a group have more hypertension than patients with inferior infarction. Differences between the two types of infarction patients may be detectable in family history as well as in associated diseases and in previous environmental exposures. A similar comparison has not been found in the available literature.

\section{Subjects}

The subjects were the survivors of a consecutive group of admissions to the hospital during the last months of 1971. The diagnoses were made in accordance with the Minnesota code. There were ror patients (69 men and 32 women) suffering from anterior infarction and 74 patients ( 56 men and 18 women) suffering from inferior infarction. The two groups were comparable with regard to age and sex (Table I).

Of the total of 175 patients, 53 had suffered one or more earlier attacks of myocardial infarction. These 53 people had suffered 66 episodes of myocardial infarction. The tendency of infarction to recur in the same site was found to be significant at a 5 per cent level (Table 2).

Since a personal interview conducted by the author was the initial source of information, only patients who had survived the acute stage of the disease could be included. Four people had to be excluded from the study because of their poor mental and physical condition. The interviews were carried out during the six months after admission to the hospital.

Received I May 1974 .

\section{Method}

Records of previous diseases were initially compiled from information supplied by the patients during the course of the interviews. Only information confirmed by the

TABLE I Population according to age and sex, and to anterior and inferior myocardial infarction

\begin{tabular}{lrrrr}
\hline & $\begin{array}{l}\text { Anterior } \\
\text { infarction }\end{array}$ & \multicolumn{2}{l}{$\begin{array}{l}\text { Inferior } \\
\text { infarction }\end{array}$} \\
\hline Year of birth & Men & Women & Men & Women \\
\hline 1929 and later & - & - & - & I \\
1928-1924 & 2 & - & 1 & - \\
1923-1919 & 6 & - & 8 & - \\
$1918-1914$ & 6 & 2 & 9 & 2 \\
$1913-1909$ & 17 & 8 & 12 & 6 \\
$1908-1904$ & 21 & 11 & 15 & 3 \\
1903-1899 & 9 & 6 & 6 & 3 \\
1898-1894 & 5 & 1 & 4 & 1 \\
$1893-1889$ & 2 & 4 & 1 & 2 \\
1888 and earlier & 1 & - & - & - \\
\hline Total & 69 & 32 & 56 & 18 \\
\hline
\end{tabular}

TABLE 2 Tendency of myocardial infarction to recur in same site

\begin{tabular}{llll}
\hline $\begin{array}{l}\text { Site of first attack of } \\
\text { myocardial infarction }\end{array}$ & \multicolumn{4}{l}{$\begin{array}{l}\text { Recurrences } \\
\text { Anterior }\end{array}$} & Inferior & \\
\hline Anterior & 26 & II & 37 \\
Inferior & 12 & 17 & 29 \\
& 38 & 28 & 66
\end{tabular}

Using Yates's correction, $\chi^{2}=3 \cdot 9, \mathrm{P}=0.049$ 
study of hospital records, the files of private and company doctors, or death certificates was used. This was also so for the recording of myocardial infarction, arterial hypertension, or diabetes mellitus in sibs and parents. The cholesterol estimations were those values obtained during the stay in hospital. Other sources of information were the census rolls and the local health insurance offices.

More than 500 different background factors were recorded. The majority of variables which revealed no significant differences were excluded from the study, but the remaining levels of significance were unlikely to be accidental, or to be due to bias produced by the interviewer.

\section{Results}

\section{a) Family history}

In the group suffering from anterior myocardial infarction there was a disproportionate number of people whose mothers had died suddenly. There was, however, no significant difference between the two groups so far as myocardial infarction in fathers and mothers was concerned.

There was a highly significant positive correlation between anterior myocardial infarction and the number of sibs who had suffered from myocardial infarction, and more of the people in the anterior group had sibs who had suffered from myocardial infarction (Table 3). The same was true for cerebrovascular insults, but there was no significant difference between the two groups so far as the occurrence of arterial hypertension in sibs was concerned.

\section{b) Social background factors}

There were no significant differences between the two groups so far as social adjustment, premorbid personality, and precipitating factors were concerned. Detrimental changes in circumstances during the 12 months before the onset of disease such as death of wife or husband, redundancy, etc. were recorded as precipitating factors. There was no significant difference in the image which the members of the two groups had of themselves. Neither group contained a significantly greater number of people who had been led to believe since infancy that they were abnormally physically or mentally weak. There was a highly significant positive correlation between inferior infarction and the number of justified spells of incapacity for work during the Io years preceding the onset of the disease (Table 4).

TABLE 3 Comparison between patients suffering from anterior and inferior myocardial infarction with regard to some circulatory diseases in sibs

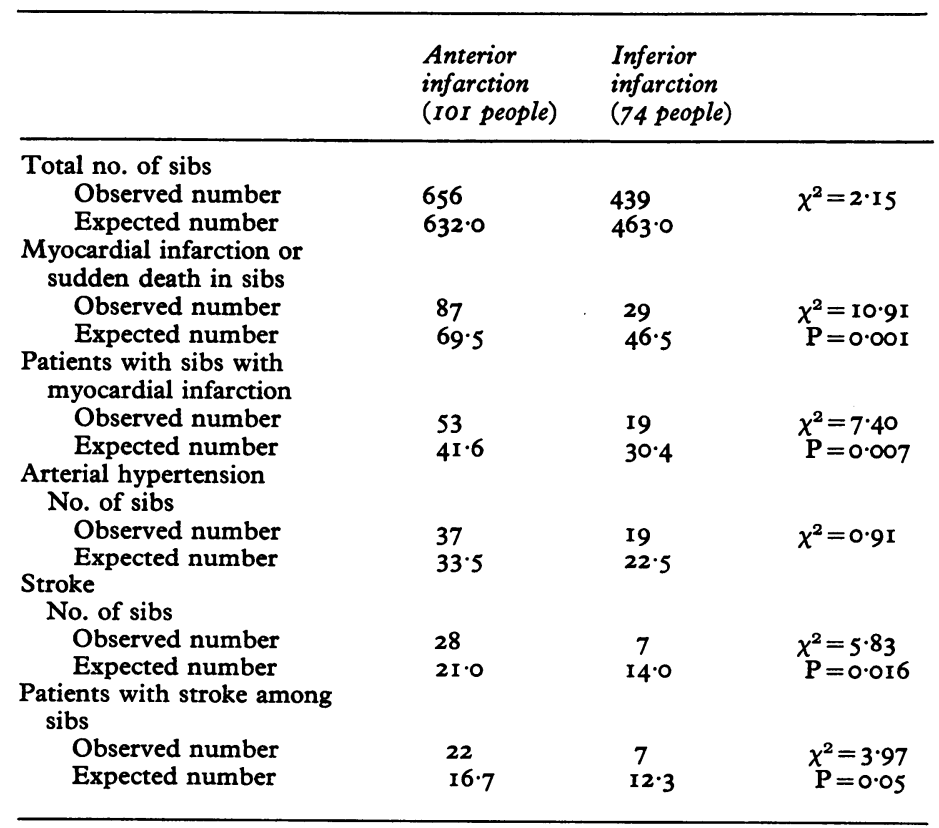


TABLE 4 Comparison between patients suffering from anterior and inferior myocardial infarction with regard to number of justified spells of incapacity for work

\begin{tabular}{llll}
\hline & $\begin{array}{l}\text { Anterior } \\
\text { infarction } \\
\text { (IOI people) }\end{array}$ & $\begin{array}{l}\text { Inferior } \\
\text { infarction } \\
\text { (74 people) }\end{array}$ & \\
\hline $\begin{array}{c}\text { Total no. of spells of } \\
\text { incapacity for work in } \\
\text { previous 10 years } \\
\text { Observed number }\end{array}$ & & & \\
$\begin{array}{l}\text { Expected number } \\
\text { Patients with no spell of } \\
\text { incapacity for work in } \\
\text { previous 10 years } \\
\text { Observed number }\end{array}$ & 745 & 647 & $\chi^{2}=10.04$ \\
Expected number & 803.4 & 588.6 & $\mathrm{P}=0.0016$ \\
\hline
\end{tabular}

\section{c) History of risk factors}

There was a highly significant positive correlation between anterior infarction and arterial hypertension, serum cholesterol values above $300 \mathrm{mg} / 100 \mathrm{ml}$, and chronic lung diseases (Table 5). There was also a significant positive correlation between anterior infarction and diabetes mellitus dependent upon drug treatment.

There was no significant difference between the two groups with regard to smoking habits or a history of angina pectoris for more than one year before the first attack of myocardial infarction.

When we consider those patients with anterior or inferior infarction only, there are 91 ( 63 men and 28 women) in the anterior group and 65 (50 men and 15 women) in the inferior group. When the above variables were related to these two smaller groups, the correlations were the same as in the whole series.

\section{Comments}

The discovery of a disproportionate number of patients in the anterior infarction group with arterial hypertension supports the working hypothesis. There was, however, a positive correlation between anterior infarction and cholesterol values above

TABLE 5 Comparison between patients suffering from anterior and inferior myocardial infarction with regard to some earlier diseases and smoking habits

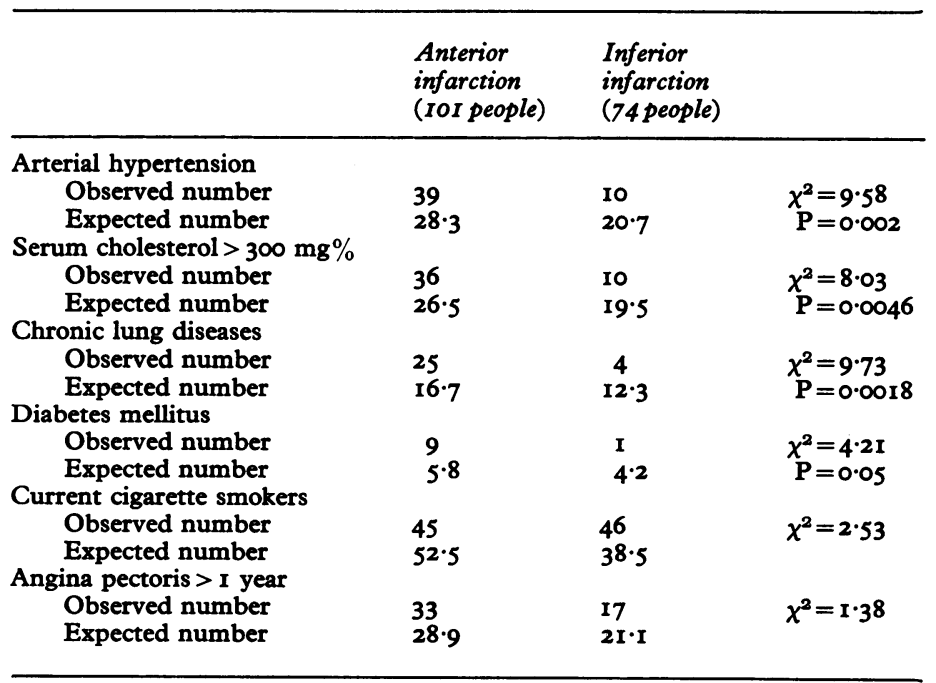


$300 \mathrm{mg} / 100 \mathrm{ml}$, diabetes mellitus, chronic lung diseases, and the number of sibs who had suffered from myocardial infarction or cerebrovascular insults.

Theoretically it is possible that those who died are different from those who survived the attack of myocardial infarction as regards the site of the disease, social background, and exposure to risk factors. This is, however, a general problem for all retrospective studies. So far there is no evidence that such selective factors have seriously biased retrospective studies. In this area about 40 per cent of patients die in the first attack of myocardial infarction.

The findings in this study are not easily explained. They do not justify the drawing of any conclusions, but do establish the need for further research.

Requests for reprints to Professor V. Lindén, Institute for Community Medicine, University of Tromsø, 9010 Asgard Sykehus, Norway. 